\title{
TRAINING SCIENCE PROCESS SKILLS USING VIRTUAL LABORATORY ON LEARNING ACID, BASE, AND SALT
}

\author{
Achmad Lutfi*1, Rusly Hidayah ${ }^{2}$ \\ ${ }^{1,2}$ Jurusan Kimia FMIPA Unesa \\ *achmadlutfi@unesa.ac.id
}

\begin{abstract}
This study aims to train the Science Process skills to students on learning Acid, Base, and Salt using the Virtual Lab. The research was conducted on the students of SMA Negeri Cerme Gresik in the year 2017/2018. During the student learning using the virtual lab and guided by Student Worksheet, during the learning process conducted an observation of student activity, after learning conducted test of learning result, and questionnaire of student response to the use of the virtual laboratory. The result of the research shows that during the active learning of the students, the learning result reaches completeness, and the students give positive responses to the use of virtual laboratory as the learning medium of acid, base and salt.
\end{abstract}

Keywords: Virtual laboratory, Science Process skills

\section{PENDAHULUAN}

Pada hakekatnya llmu kimia dipandang sebagai proses dan produk. Ilmu Kimia sebagai produk meliputi sekumpulan pengetahuan yang terdiri atas fakta, konsep dan prinsip kimia. Ilmu Kimia atau Kimia sebagai proses meliputi keterampilan dan sikap yang dimiliki oleh para ilmuan untuk memperoleh dan mengembangkan pengetahuan kimia atau produk kimia. Dalam dunia pendidikan pembelajaran kimia harus memberikan pengalaman belajar secara langsung melalui penggunaan dan pengembangan keterampilan proses dan sikap ilmiah [1]. Oleh karena itu, pembelajaran kimia tidak boleh mengesampingkan proses ditemukannya konsep-konsep kimia, sehingga keterampilan proses sains sangat penting dimiliki siswa dalam rangka membangun konsep-konsep kimia. Untuk membangun konsep-konsep dan pengembangan keterampilan proses, diperlukan suatu metode pembelajaran yang tepat, diantaranya adalah praktikum. Metode praktikum dianggap tepat dalam membangun konsep siswa karena dengan praktikum, siswa lebih mudah memahami konsep dengan cara membangun sendiri konsep-konsep tersebut. Pembelajaran IPA termasuk Kimia yang menarik, menyenangkan layak sesuai dengan konteks, serta didukung oleh ketersediaan waktu, keahlian, sarana, dan presarana merupakan kegiatan yang tidak mudah untuk dilaksanakan. Seorang guru dituntut memiliki kemampuan dan kreativitas yang cukup agar pembelajaran dapat diselenggarakan secara efektif dan efisien [2].

Denganberkembangnya ilmu pengetahuan dewasa ini maka tidaklah mungkin lagi seorang guru mengajarkan semua fakta dan konsep kepada para siswanya. Jika pun dipaksakan untuk dapat terlaksananya maka guru akan mengambil jalan pintas yaitu mengajarkan secara terburuburu dengan metode ceramah. Akibatnya, siswa mungkin akan memiliki banyak pengetahuan tetapi tidak dilatih untuk menemukan pengetahuan, meliputi keterampilan memformulasikan hipotesis, menamakan variabel mengontrol variabel, membuat definisi yang operasional, melakukan eksperimen, menginterpretasi data, dan melakukan penyelidikan. Kita semua tentunya telah mengelahui bahwa pada praktiknya apabila seseorang melakukan penyelidikan atau penelitian atau percobaan, umumnya ia menggunakan beberapa macam keterampilan proses secara bersamaan. Keterampilan proses IPA yang terintegrasi meliputi memformulasi hipotesis, menamai 
variabel, membuat definisi operasional, melakukan eksperimen, mengintepretasikan data dan melakukan penyelidikan. Keterampilan proses IPA terintegrasi merupakan kombinasi dan keterampilan penyelidikan yang merupakan kombinasi dari keterampilan IPA dasar seperti mengobservasi, melakukan pengukuran, keterampilan proses IPA yang terintegrasi biasanya diperkenalkan kepada siswa yang telah memiliki keterampilan dasar IPA yang mendasar.

Selain dapat menunjang dalam membangun konsep, metode praktikum juga dapat digunakan untuk mengembangkan keterampilan proses sains karena dalam praktikum terdapat kegiatan-kegiatan yang berkaitan dengan keterampilan proses sains, misalnya, kegiatan mengamati, menafsirkan pengamatan, meramalkan, menggunakan alat dan bahan, menerapkan konsep, merencanakan penelitian, mengkomunikasikan hasil penelitian dan mengajukan pertanyaan. Metode praktikum jarang dilakukan dalam pembelajaran kimia di sekolah-sekolah [3], hal ini terjadi karena berbagai kendala seperti, tidak tersedianya fasilitas, biaya yang relatif mahal, terbatasnya alokasi waktu pembelajaran, dan kesukaran melakukan persiapan sebelum praktikum, fakta ini harus ada alternatif pemecahannya, yaitu pembelajaran dengan laboratorium virtual. Untuk menanggulangi kendalakendala dalam pelaksanaan praktikum dapat diatasi dengan pemanfaatan teknologi informasi dan komunikasi (TIK), seperti komputer [3]. Dengan bantuan media berupa komputer siswa dapat melakukan pembelajaran kimia dalam bentuk eksperimen semu (virtual lab).

Pada implementasi kurikulum 2013 dalam pembelajaran, guru sangat dituntut untuk mengembangkan kegiatan pembelajaran. Kegiatan pembelajaran dirancang untuk memberikan pengalaman belajar yang melibatkan proses mental dan fisik melalui interaksi antar siswa, siswa dengan guru, lingkungan, dan sumber belajar lainnya dalam rangka pencapaian Kompetensi Dasar. Pengalaman belajar yang dimaksud dapat terwujud melalui penggunaan pendekatan pembelajaran yang bervariasi dan berpusat pada siswa. Pengalaman belajar memuat kecakapan hidup yang perlu dikuasai peserta didik. Pada kurikulum 2013 ini melatihkan 5M diantaranya yaitu mengamati, menanya,mengumpulkan data, mengasosiasikan, mengkomunikasikan hasil. Karenanya guru perlunya memfasilitasi agar siswa dapat melakukan pengamatan terhadap pemodelan/demonstrasi oleh guru atau ahli, siswa menirukan, selanjutnya guru melakukan pengecekan dan pemberian umpan balik, dan latihan lanjutan kepada siswa.

Di Sekolah Menengah Atas terdapat beberapa materi kimia yang mengharuskan siswa melakukan praktikum di laboratorium salah satu contohnya adalah materi Asam, Basa, dan Garam. Dalam materi pokok Asam, Basa, dan Garam tidak semua materi dapat dipahami oleh siswa. Materi tersebut memerlukan kegiatan praktikum di laboratorium untuk menunjang ketuntasan belajar siswa, terdapat kendala pelaksanaan praktikum antara lain tidak tersedianya labolatorium, keterbatasan bahan dan alat. Hal tersebut dapat dilakukan dengan media virtual lab sehingga siswa dapat melakukan praktikum sendiri secara virtual. Media ini diharapkan mampu meningkatkan kemampuan keterampilan proses siswa yang menjadi tuntutan pembelajaran Kimia.

Laboratorium yang digunakan bersarana komputer berupa visualisasi laboratorium dapat digunakan dalam praktikum untuk menentukan sifat asam, basa, dan garam berdasarkan $\mathrm{pH}$-nya dengan menggunakan alat $\mathrm{pH}$ meter. Tersedia juga beberapa macam larutan asam kuat, asam lemah, basa kuat, basa lemah, dan larutan garam yang dapat dimanipulasi konsentrasinya. Siswa dapat merancang percobaan sendiri dan melakukannya dengan alat yang tersedia. Saat ini telah ada media interaktif virtual lab yang telah dinyatakan layak untuk digunakan sebagai media dalam melakukan praktikum pada materi pokok Asam, Basa, dan Garam, oleh karena itu perlu diterapkan dalam pembelajaran di kelas agar dapat diperoleh data tentang pemanfaatan laboratorium virtualtersebut untuk melatih keterampilan proses sains pada pembelajaran pokok bahasan Asam, Basa, dan Garam.

\section{METODE}

Penelitian dilakukan di SMA Negeri Cerme Gresik pada semester Gasal tahun ajaran 2017/2018. Sebelum pembelajaran 
dilakukan tes awal dan setelah pembelajaran dilakukan tes akhir tentang kemampuan keterampilan proses sains, selama pembelajaran dilakukan siswa menggunakan lembar kerja siswa dan dilakukan pengamatan aktivitas siswa. Angket diberikan setelah pembelajaran selesai dan juga dilakukan wawancara untuk melengkapi data angket.

Data yang diperoleh berupa aktivitas siswa diprosentasikan untuk menentukan tingkat aktivitas siswa selama pembelajaran. Data hasil belajar siswa ditentukan ketuntasan kemampuan keterampilan proses sains, yang meliputi: mengamati, mengklasifikasi, mengukur, inferensi dan menarik kesimpulan dengan kriteria ketuntasan klasikal, yaitu 80\% dan Kriteria Ketuntusan Minimal 75\%. Data tanggapan siswa diprosentasikan dan dibandingkan dengan kriteria yang ditentukan, yaitu $\geq 70 \%$ menyatakan respon positif.

\section{HASILDANPEMBAHASAN}

Data yang diperoleh selama penelitan berupa aktivitas siswa mengikuti pembelajaran, hasil belajar yang berupa skor kemampuan keterampilan proses sains pada pembelajaran asam, basa, dan garam, dan angket tanggapan penggunaan laboratorium virtual dalam pembelajaran Asam, Basa, dan Garam, serta wawancara.

\section{Aktivitas Siswa}

Pengamatan aktivitas siswa dilakukan pada rentang waktu 3 menit oleh dua observer selama 90 menit, hasil pengamatan disajikan pada Tabel 1.

Tabel 1 Aktivitas Siswa

\begin{tabular}{|c|c|c|c|}
\hline \multirow[b]{2}{*}{ No } & \multirow[b]{2}{*}{ Aktivitas } & \multicolumn{2}{|c|}{ Hasil Pengamatan } \\
\hline & & $\begin{array}{c}\text { Observer } \\
1\end{array}$ & $\begin{array}{c}\text { Observer } \\
2\end{array}$ \\
\hline 1 & $\begin{array}{l}\text { Siswa mengikuti } \\
\text { pelajaran di kelas }\end{array}$ & $20,00 \%$ & $16,67 \%$ \\
\hline 2 & $\begin{array}{l}\text { Siswa } \\
\text { menggunakan } \\
\text { laboratorium virtual }\end{array}$ & $16,67 \%$ & $20,00 \%$ \\
\hline 3 & $\begin{array}{l}\text { Siswa bekerja sama } \\
\text { dengan baik di } \\
\text { dalam kelompok }\end{array}$ & $20,00 \%$ & $23,33 \%$ \\
\hline 4 & $\begin{array}{l}\text { Siswa antusias } \\
\text { bertanya yang } \\
\text { belum diketahui }\end{array}$ & $13,33 \%$ & $10,00 \%$ \\
\hline 5 & $\begin{array}{l}\text { Siswa bersemangat } \\
\text { mencari data }\end{array}$ & $20,00 \%$ & $23,33 \%$ \\
\hline 6 & Kegiatan yang tidak & $10,00 \%$ & $6,66 \%$ \\
\hline
\end{tabular}

\begin{tabular}{lrcc}
\hline \multirow{2}{*}{ No } & \multirow{2}{*}{ Aktivitas } & \multicolumn{2}{c}{ Hasil Pengamatan } \\
\cline { 3 - 3 } & & Observer & Observer \\
& & 1 & 2 \\
\hline \multicolumn{2}{|c}{ relevan } & \\
\hline
\end{tabular}

Data di atas memperlihatkan aktivitas siswa selama pembelajaran kategori baik, artinya siswa selama pembelajaran telah mengikuti pelajaran sesuai rencana, siswa dapat melakukan pembelajaran dengan laboratorium virtual, siswa antusias mengikuti pembelajaran dan keinginan bertanya dan mencari data telah muncul selama pembelajaran. Hal ini sesuai hasil penelitian bahwa dengan menggunakan media yang sesuai akan memunculkan aktivitas siswa yang baik pula [4]. Selama pembelajaran kegiatan yang tidak relevan paling kecil terjadi, sehingga dapat dikatakan dengan laboratorium virtual dan LKS dapat memperkecil aktivitas siswa yang tidak diinginkan. Kegiatan yang tidak relevan, yaitu beraktivitas yang tidak terkait dengan pembejaran, antara lain menanyakan cara mengoperasikan laboratorium virtual, yaitu memulai atau menutup program, menanyakan kaitan antara LKS dan laboratorium virtual, ke kamar kecil, dan melakukan/mencoba di luar LKS yang disediakan.

\section{Kemampuan Keterampilan Proses Sains}

Tes kemampuan yang disusun berdasarkan tujuan pembelajaran dilakukan setelah pembelajaran selesai, yang meliputi: mengamati, mengklasifikasi, mengukur, inferensi dan menarik kesimpulan dengan berdasarkan KKM $75 \%$ dan ketuntasan klasikal sebesar $80 \%$, hasil tes kemampuan disajikan pada Tabel 2 dan Tabel 3.

Tabel 2 Keterampilan Proses Sains Tiap Aspek

\begin{tabular}{llccc}
\hline No & Aspek & $\begin{array}{c}\text { Jumlah } \\
\text { siswa }\end{array}$ & $\begin{array}{c}\text { Jawaban } \\
\text { Benar } \\
\text { Pretest }\end{array}$ & $\begin{array}{c}\text { Jawaban } \\
\text { benar } \\
\text { Posttes }\end{array}$ \\
\hline 1 & Mengamati & 32 & $46,87 \%$ & $81,25 \%$ \\
\hline 2 & Mengukur & 32 & $48,13 \%$ & $82,50 \%$ \\
\hline 3 & Mengklasifikasi & 32 & $43,12 \%$ & $63,74 \%$ \\
\hline 4 & Inferensi & 32 & $31,25 \%$ & $65,62 \%$ \\
\hline 5 & $\begin{array}{l}\text { Menarik } \\
\text { kesimpulan }\end{array}$ & 32 & $28,12 \%$ & $61,87 \%$ \\
\hline
\end{tabular}

Data di atas memperlihatkan perubahan kemampuan keterampilan proses sains pada tiap aspek keterampilan proses sains, aspek 
tertinggi yang dicapai pada aspek mengukur, kemudian disusun aspek mengamati, aspek inferensi, mengklasifikasi, dan menarik kesimpulan. Berdasar data di atas memperlihatkan aspek menarik kesimpulan masih rendah atau dirasakan lebih sulit dibanding aspek yang lainnya. Keterampilan pengukur memerlukan kemampuan untuk menggunakan alat ukur secara benar dan kemampuan untuk menerapkan cara perhitungan dengan alat-alat ukur. Konsep dasar ukuran kemudian dikembangkan kepada sistem pengukuran yang telah ada dan umum digunakan atau telah terstandarkan [2]. Adanya laboratorium virtual telah dapat melatih kemampuan siswa dalam melakukan pengukuran.

Aspek menarik kesimpulan paling rendah, hal ini dapat dipahami bahwa menarik kesimpulan merupakan keterampilan proses sains yang lebih sulit dibanding aspek mengamati, mengklasifikasi, infernsi, dan mengukur [2]. Mengamati merupakan pengalaman yang didapat melalui panca indra, mengamati merupakan keterampilan proses sains yang paling dasar, sedangkan inferensi merupakan penjelasan dari suatu hasil pengamatan. Hendaknya siswa dapat membedakan antara mengamati dan menginferensi. Klasifikasi, adalah mengatur atau membagi objek, kejadian, atau informasi tentang objek ke dalam kelas menurut metode atau sistem tertentu [5].

\section{Tabel 3 Kemampuan Keterampilan} Proses Sains

\begin{tabular}{cccc}
\hline \multirow{2}{*}{ Kondisi } & Jumlah & \multicolumn{2}{c}{ Ketuntasan } \\
\cline { 3 - 4 } & Siswa & Jumlah & $\%$ \\
\hline Pre tes & 32 & 2 & 6,25 \\
\hline Post tes & 32 & 31 & 96,8 \\
\hline
\end{tabular}

Hasil posttes padaTabel 3, menunjukkan telah tercapai ketuntasan klasikal, artinya adanya pembelajaran Asam, Basa, dan Garam dengan menggunakan laboratorium virtual meningkatkan pemahaman siswa tentang keterampilan proses sains. Hasil tersebut sesuai dengan penelitian Wardani [6] bahwa kegiatan praktikum dapat mengembangkan keterampilan proses sains. Dan hasil belajar siswa aspek kognitif berpengaruh atas digunakan laboratorium virtual [3]. Hal ini juga didukung pula hasil wawancara kepada siswa, yang menyatakan dengan belajar dengan laboratorium virtual menjadi faham tentang Asam, Basa, dan Garam.

Penggunaan laboratorium virtual telah mampu membelajarkan keterampilan proses sains, hasil ini senada dengan hasil penelitian Wardoyo [7] bahwa laboratorium virtual dapat digunakan dalam belajar dengan praktikum secara virtual (maya) dan dapat membangun pembelajaran bermakna. Juga hasil penelitian lain yang menyatakan pembelajaran berbasis laboratorium virtual dapat meningkatkan penguasaan konsep [8].

\section{Tanggapan Siswa}

Hasil tanggapan siswa atas penggunaan laboratorium virtual pada pebelajaran asam, basa, dan garam disajikan pada Tabel 4 .

Tabel 4 Tanggapan Siswa

\begin{tabular}{|c|c|c|c|}
\hline No & Pernyataan & $\begin{array}{c}\mathrm{Ya} \\
(\%)\end{array}$ & $\begin{array}{c}\text { Tidak } \\
(\%)\end{array}$ \\
\hline 1 & $\begin{array}{l}\text { Dengan kegiatan pembelajaran } \\
\text { dengan laboratorium virtual } \\
\text { yang telah saya ikuti, lebih } \\
\text { mudah memahami materi yang } \\
\text { diajarkan. }\end{array}$ & 93,75 & 6,25 \\
\hline 2 & $\begin{array}{l}\text { Dengan kegiatan pembelajaran } \\
\text { yang telah saya ikuti, saya } \\
\text { menjadi lebih aktif mengikuti } \\
\text { pembelajaran. }\end{array}$ & 87,5 & 12,5 \\
\hline 3 & $\begin{array}{l}\text { Kegiatan pembelajaran tadi } \\
\text { memudahkan saya dalam } \\
\text { memecahkan permasalahan } \\
\text { atau menjawab soal yang } \\
\text { diberikan. }\end{array}$ & 96,87 & 3,13 \\
\hline 4 & $\begin{array}{l}\text { Kegiatan pembelajaran ini } \\
\text { membantu saya mengenal } \\
\text { beberapa alat percobaan kimia. }\end{array}$ & 90,6 & 9,4 \\
\hline 5 & $\begin{array}{l}\text { Kegiatan pembelajaran tadi } \\
\text { dapat membuat saya lebih } \\
\text { semangat dalam belajar kimia }\end{array}$ & 100 & 0 \\
\hline
\end{tabular}

Hasil di atas memperlihatkan siswa memberikan tanggapan positif tiap pernyataan, yaitu mulai sebesar $87,5 \%$ hingga $100 \%$. Artinya bahwa siswa merasa terbantukan oleh media laboratorium virtual dalam belajar Asam, Basa, dan Garam. Siswa merasakan kegiatan pembelajaran dengan laboratorium virtual memudahkan dalam memahami yang diajarkan, memberikan semangat belajar kimia, dapat mengenal alat percobaan kimia, hal ini terbukti selain dari angket juga hasil belajar yang diperolehnya, yakni mengalami ketuntasan klasikal pada akhir pembelajaran dibanding pada sebelum 
pembelajaran. Ketertarikan siswa pada penggunaan laboratorium virtual sebagai media pembelajaran menjukkan pemilihan media yang sesuai dengan kebutuhan siswa dan tujuan pembelajaran, hal ini sesuai dengan pendapat Sadiman [9].

Pembelajaran dengan menggunakan laboratorium virtual dianggap siswa menyenangkan dan mudah dan bahkan lebih menarik dengan dianggapnya mudah sebagian besar siswa lebih memahami hal ini terbukti dari hasil belajar yang diperolehnya setelah pembelajaran. Hasil wawancara mendukung hasil tersebut yang menyatakan bahwa belajar dengan laboratorium vistual menyenangkan dan lebih mudah mengerti $\mathrm{pH}$ tanpa praktikum di laboratorium riil. Hal ini sesuai dengan fungsi media pembelajaran yang dapat digunakan untuk menyampaikan informasi penerima yang dapat merangsang pikiran, perasaan, perhatian, minat sehingga terjadi proses belajar [5]. Pemilihan media pembelajaran dihadapkan pada kondisi: disesuikan dengan tujuan pembelajaran, memodifikasi media yang ada, atau merancang media baru [10]. Hasil belajar dan hasil tanggapan siswa memperlihatkan media yang dipilih sesuai dengan karakteristik siswa dan tujuan pembelajaran.

\section{SIMPULAN DAN SARAN \\ Simpulan}

Hasil penelitian menunjukkan pembelajaran Asam, Basa, dan Garam dengan laboratorium virtual dapat melatihkan keterampilan proses sains dengan ditandai aktivitas siswaselama pembelajaran, ketuntasan hasil belajar keterampilan proses sains, dan tanggapan positif siswa atas digunakannya laboratorium virtual.

\section{Saran}

1. Guru masih menggunakan laboratorium riil karena penggunaan laboratorium virtual hanya mampu melatihkan keterampilan melatihkan keterampilan tertentu saja, sedangkan keterampilan yang lainnya, misalnya menuangkan, merangkai alat, alat dan lain-lainnya belum dapat dilakukan dengan laboratorium virtual.

2. Hendaknya guru memanfaatkan laboratorium virtual sebagai salah satu alternatif guru untuk melatih keterampilan proses sains dalam pembelajaran Kimia di SMA.

\section{UCAPAN TERIMA KASIH}

Ucapan terima kasih disampaikan kepada Ketua Jurusan Kimia, Dekan FMIPA, dan Rektor Unesa atas pemberian dana penelitian kebijakan sehingga dapat dilakukan penelitian tentang penggunaan laboratorium virtual untuk melatih keterampilan proses sains pada pembelajaran Asam, Basa, dan Garam. Terima kasih disampaikan pula kepada Kepala Kepala, Guru Kimia, dan siswa SMA Negeri Cerme Gresik yang telah membantu pelaksanaan penelitian ini, serta mahasiswa Prodi Pendidikan Kimia FMIPA Unesa yang membantu melakukan penelitian.

\section{DAFTAR PUSTAKA}

[1] BSNP. (2016). Peraturan Menteri Pendidikan dan Kebudayaan nomor 20 Tahun 2016tentang Standar Kompetensi Lulusan untuk Satuan Pendidikan Dasar dan Menengah. Jakarta: Kemdikbud.

[2] Sapriti, A., Hartinawati, Sulaiman, M., Budiastra A. A., Rochiyah, I., Rumanta, M., Rintansa, R., Nasution, N., Sulistyarini, S. (2014). Pembelajaran IPA di SD Buku Materi Pokok PDGK 4201 Modul 1-9. Jakarta: Universitas Terbuka

[3] Hamida, N Mulyani, B., Utami, B. (2013). Studi Komparasi Penggunaan Laboratorium Virtual dan Laboratorium Riil tehadap Prestasi Belajar ditinjau dari Kreativitas Siswa pada Materi Pokok Sistem Koloid SMA Negeri 1 Banyudono. Jurnal Pendidikan Kimia (JPK)UNS: Vol. 2 No. 2 ISSN: 2337-9995Th 2013. Solo: Prodi Pendidikan Kimia UNS.

[4] Lutfi, A. (2013). Memotivasi Siswa Belajar Sains Dengan Menerapkan Media Pembelajaran Komik Bilingual. Jurnal Pendidikan dan Pembelajaran, Terakreditasi Ditjen Dikti, 20 No. 2 (Okt 2013), Universitas Negeri Malang: 152-159.

[5] Carin, A. A. (1993). Teaching Science through Discovery. New York: Macmullan Publishing Company.

[6] Wardani, S. (2008). Pengembangan Keterampilan Proses Sains Dalam 
Pembelajaran Kromatografi Lapis Tipis a, Melalui Praktikum Skala Mikro. Jurnal Inovasi Pendidikan Kimia, Vol .2, No. 2, 2008, hlm 317-322. Semarang: Unnes.

[7] Wardoyo, U. (2008). Pembuatan Aplikasi Mutimedia Untuk Pembelajaran Praktikum Secara Virtual Pada Konsep Struktur Atom. Tesis. Bandung: Jurusan Kimia MIPA ITB.

[8] Suarja, Z. A. (2015). Penggunaan Laboratorium Virtual Pada Pembelajaran Biologi di SMA Kota Banda Aceh. Jurnal Bio-Natural Vol. 2,
No. 2 Sep - Feb 2015, h. 33-38. Bina Bangsa Meulaboh.

[9] Sadiman, A. (2012). Media Pendidikan Seri Pengertian, Pengembangan dan Pemanfaatannya . Jakarta: PT Raja Grafindo Persada.

[10] Smaldino, S., Lowther, D. L., \&Russell, J. D. (2012). Intructional Technology \& Media For Learning: Teknologi Pembelajaran dan Media untuk Belajar. Edisi kesembilan. Terjemahan Arif Rahman. Jakarta: Kencana. 